\title{
The Problems in the Process of Modeling of Water Use Systems
}

\author{
Oleg Naumenko*, Inna Timofeeva and Elena Lavrova \\ State and Municipal Management, The Russian Presidential Academy of National Economy and \\ Public Administration (Smolensk branch), Russia; \\ naumenko06@mail.ru, innatimoff@mail.ru, e.v.lavrova@list.ru
}

\begin{abstract}
The problems of methods of rational water use consideration actual today. Mathematical models of water use systems possess a great number of the features allocating them in an independent class of models of applied character. This specificity is caused, first of all, by features of modeled objects, the importance of water, its dual character. Water is, on the one hand, a natural renewed resource for economic activities, and on the other hand, - one of elements of inhabitancy of the person and life existence on the Earth. Thereof circumstances urged to provide natural-technical systems of water use not only economic requirements of society, but also to realize all necessary ecological (nature protection) functions. Mathematical modeling of water use systems represents multidimensional procedure of construction of the cooperating versatile problems submitting to principle of stage-by-stage detailed elaboration. Thus objects of modeling are difficult organized multi component hierarchical dynamic operated systems functioning in the conditions of stochasticity of natural processes, and also step-type behavior and uncertainty of some parameters.
\end{abstract}

Keywords: Mathematical Modeling, Preservation of Water Resources, Water-economic Systems, Water Use Systems

\section{Introduction}

The urgency of preservation of water resources in the Central Asian region, and, in particular in territory of Uzbekistan is conclusive. Therefore, scientists of different branches of knowledge including mathematics, try to create models of systems of water use on immediate prospects.

\section{Materials and Methods}

Mathematical models of systems of water use possess a great number of the features allocating them in independent class of models of applied character. This specificity is caused, first of all, by features of modeled objects, the importance of water, its dual character. Water is, on the one hand, a natural renewed resource for economic activity, and on the other hand, - one of elements of inhabitancy of the person and life existence on the Earth. Thereof this circumstances natural-technical systems of water urged to provide use not only economic requirements of society, but also to realize all necessary ecological functions. The specified dualism of water-economic systems causes polycriterial of corresponding mathematical models. The best economic variant of parameters and modes of functioning of system almost always doesn't correspond to optimum ecological condition of water objects, and such condition in turn, doesn't provide comprehensible economic-industrial level. Therefore, in

*Author for correspondence 
global sense some compromise variant of development and functioning of water-economic systems is always searched ${ }^{1}$.

The choice of similar variant depends on set of various factors. For example, the economic component is defined by capital expenses and operational costs for water delivery to water users, water preparation, building and operation of treatment facilities, dams and waste constructions, protective actions from harmful influence of waters, etc.

Economic efficiency of systems of water use is described by communication between quantity of used water resources and output (production functions). The ecological component is defined by quality of natural waters, i.e. depends on structure and concentration of every possible component in water. Values of these components are caused by set of physical, chemical, biological and other processes. Thus, from applied positions mathematical models of systems of water use have strongly pronounced interdisciplinary character. Statement and formalization of corresponding problems demands consideration of the complex problem of rational water use from various aspects.

Water-economic systems represent dynamic operated systems as their functioning and development occurs in time. The processes connected with course of natural waters, water delivery to water users, receipt and distribution of polluting substances, their transformation in the water environment etc. also are dynamic. Management of water use systems consists in a choice of parameters of created or reconstructed systems, and also in change of characteristics and (or) modes of functioning already existing. Thus there is an active intervention in various components of natural processes and ecosystems. All natural processes have stochastic character, being not only non-stationary, but often even not possessing of ergonomic property (for example, owing to influence of global climate changes). The account of these factors plays an essential role in adequacy of created mathematical models to real processes and water use systems.

Important feature of systems of water delivery consists that the choice of operating influences in these systems is carried out by a hierarchical principle. It concerns not only long-term planning of water use, but even to an operational administration. Certainly, the number of levels of hierarchy depends both on scale of water object and complexity of its structure. Hierarchy of management doesn't mean, however, full submission of underplaying operating structures to the top controls. As a rule, submission is expressed that at higher level the general (strategic) decisions are made, and at the subsequent levels they are stage by stage taking concretized with account of local conditions.

Direct consequence of subordination principle of the structures responsible for management by water use is the hierarchical structure of the water-economic systems providing stage-by-stage detailed elaboration of accepted decisions. Realization of this principle is directly connected with the decision of such problems as:

- Concrete definition of the purposes and problems at transition from higher level of decision-making to the subsequent levels;

- Decomposition of the general system of models on subsystems and problems;

- Division into districts of large region on the territories characterized by relative uniformity of those or other parameters essential to given problem;

- Carrying out of procedures of averaging of the data within these territories;

- Working out of various indicators.

The general problem of the information plan consists in necessity of the coordination of volume and accuracy of the given information to detail of accepted decisions level (as accuracy of results of modeling is connected with accuracy of the initial information). Additional difficulty is thus caused by that for a number of the data there is a top limit of technologically achievable accuracy. 
Meanwhile, to specify numerical value of such limit is possible extremely seldom.

Therefore, here it is necessary to start with some expert estimations, and after the analysis of all data set is necessary to choose the least exact information which defines "reasonable" accuracy of modeling received results. As it is easy to understand, with growth of object scales and its complexity the limit of achievable accuracy of modeling only decreases.

All natural processes influencing functioning and development of water-economic systems are naturally interpreted as continuous. It is impossible to say, however, about all parameters of management and especially about technical characteristics of water-economic and water security constructions that cause occurrence in many models of water use systems essentially discrete variables. Besides step-type behavior is often connected by the data gathers irregularly. Sometimes some discrete approximation is entered menacingly, proceeding from computing reasons. Thus, step-type behavior of some parameters is one of attributes of models of considered type. In spite of the fact that the decision of mathematical problems with discrete variables usually essentially is more difficult, than in a continuous case, it often doesn't interfere with their decision that is connected with specificity of the majority of real water-economic systems structure.

Thus, mathematical modeling of water use systems represents multidimensional procedure of construction of the cooperating versatile problems submitting to a principle of stage-by-stage detailed elaboration. Thus objects of modeling are difficult organized multi component hierarchical dynamic operated systems functioning in the conditions of stochasticity of natural processes, and also step-type behavior and some parameters uncertainty.

It is natural that computer realizations of such problems possess properties, characteristic for the big program complexes. The software of such complexes is subdivided into the core (problem) and auxiliary (serving). The general software is directly focused on the decision of those problems which in the set form system of water use mathematical models. Auxiliary maintenance consists of control facilities of the data set (their input, replen- ishment, removal, updating, protection, integrity check, etc.). Besides, the structure of auxiliary maintenance includes visualization tools of modeling results, graphic systems, dialogue means, and also means of various models among themselves co-jointing (program interfaces) and other similar elements.

The special place among the auxiliary software of water use mathematical models is occupied with Geoinformation Systems (GS). Allocation of GS among other systems of accumulation and management of the information is caused by their orientation on spatiallycoordinated data, and also possibilities of gathering, storage, coordination and processing of this data in the standardized format, maintenance of the information delivery to the user in the form most convenient for him (cards, schemes, tables, etc.). Within the limits of water use system models some subspecies of GS can be formed: ground and water resources, soils and a lay of land, wood resources, an economy of big cities, etc. Each subspecies of GS are under construction as the multipurpose information-modeling system functioning in a complex with problems.

Hundreds specialized publications are devoted to requirements for technology of working out, testing, documenting, updating and other elements of construction and development of the big program complexes. The main difference of such complexes from the research programs created for the scientific analysis of any concrete problem consists in the following. Research programs don't demand so special attention to the auxiliary software as their developers and consumers even if aren't the same person, as a rule, represent the uniform scientific personnel studying the given problem. Computer systems of rational water use models represent wide application software products. Owing to a variety of solved problems such system has extremely great volume. It is created not in one step and possesses strongly pronounced block structure. Therefore, from the very beginning it is necessary to provide an openness of this system for connection to it of new models, and working out of the software to carry out strictly adhering to a modular principle. In connection with rapid growth of personal computers 
technical and program possibilities the question on qualitative performance of the models service software and the corresponding documentation of users has risen even more sharply. Meanwhile, it has led to realization of similar program complexes continues to become more and more labor-consuming and expensive. Therefore, it makes sense to combine working out of new program complexes with modernization numerous developed before, first of all at the expense of perfection their auxiliary software.

The general principles of construction of models of water use systems formulated above, at first sight, seem obvious. However, in the course of concrete models realization developers no means always manage to execute them. In one cases errors of systematic technical plan lead to excessive developers and user's expenditures of labor, in other cases they can lead to impossibility of model application. It is possible to result some examples of such discrepancies which illustrate non-observance consequences of systematic technical principles.

In the early 80 s of the $\mathrm{XX}^{\text {th }}$ century the complex model of parameters choice of actions for river drain of the small and average rivers regulation for the purpose of requirements of water users and protection against high waters maintenance ${ }^{2}$ is realized. Within the limits of this model it was possible to solve two problems: to choose an arrangement and useful volumes of water basins on water use conditions, and also to define technical parameters of dams and waste constructions on conditions of protection against a drain of high waters and rain high waters. As search of an optimum variant in each of problems was spent under the same step-by-step scheme of dynamic programming from sources of a river network to a closing alignment, the program complex has been united in some system which central modules solved both problems simultaneously, or any one of them. However, introduction of this model within 5-7 years on numerous real objects has shown that applied users never addressed to the joint decision of both problems. They preferred to receive at first a rough estimate on the first problem, and only after long time to pass to the decision of the second problem at the chosen characteristics and site of water basins. Thus, the model has appeared as superfluous: one of modes of its work was never realized. The reason of it consisted in infringement formulated above a principle of stage-by-stage detailed elaboration. Really, at a choice of a site and useful volumes of water basins is enough to be limited to a rough estimate of a relief of water basin bowl, and cost data receive on the basis of the integrated specific expenses. Thus settlement intervals of time can be taken in a cut of year's seasons. Such information is accessible to the designer at a drawing up stage of the basin scheme or the project feasibility project.

The choice of constructive characteristics of dams and waste constructions is carried out already at later design stages. It demands much more detailed initial information inaccessible at the first stages.

Thus in the course of modeling spent excessive work on realization of such mode of calculations which can't find applications in practice.

\section{Results and Discussion}

Now we will consider the basic classes of models of water resources management. Research of problems and development of corresponding administrative decisions for water economic systems and their parts is inconceivable without application of the device of mathematical modeling. Difficult natural-technical complexes represent the dynamic systems developing and functioning under the influence of numerous stochastic natural factors, having various and not always certain communications with other natural and economic formations. Acceptance of the proved decisions on management of water use means generation and comparison of numerous variants of development and system functioning. Thus direct experimental check of compared variants is not represented possible. Therefore, the device of mathematical modelling appears unique alternative to acceptance of forcible decisions. A lot of levels of management and a lot of aspects of conditions of development of operating influences define necessity of splitting of all management problem on private under problems for which creation the special mathematical models united in complete System of Support of Decision-Making (SSDM) is required. Thus 


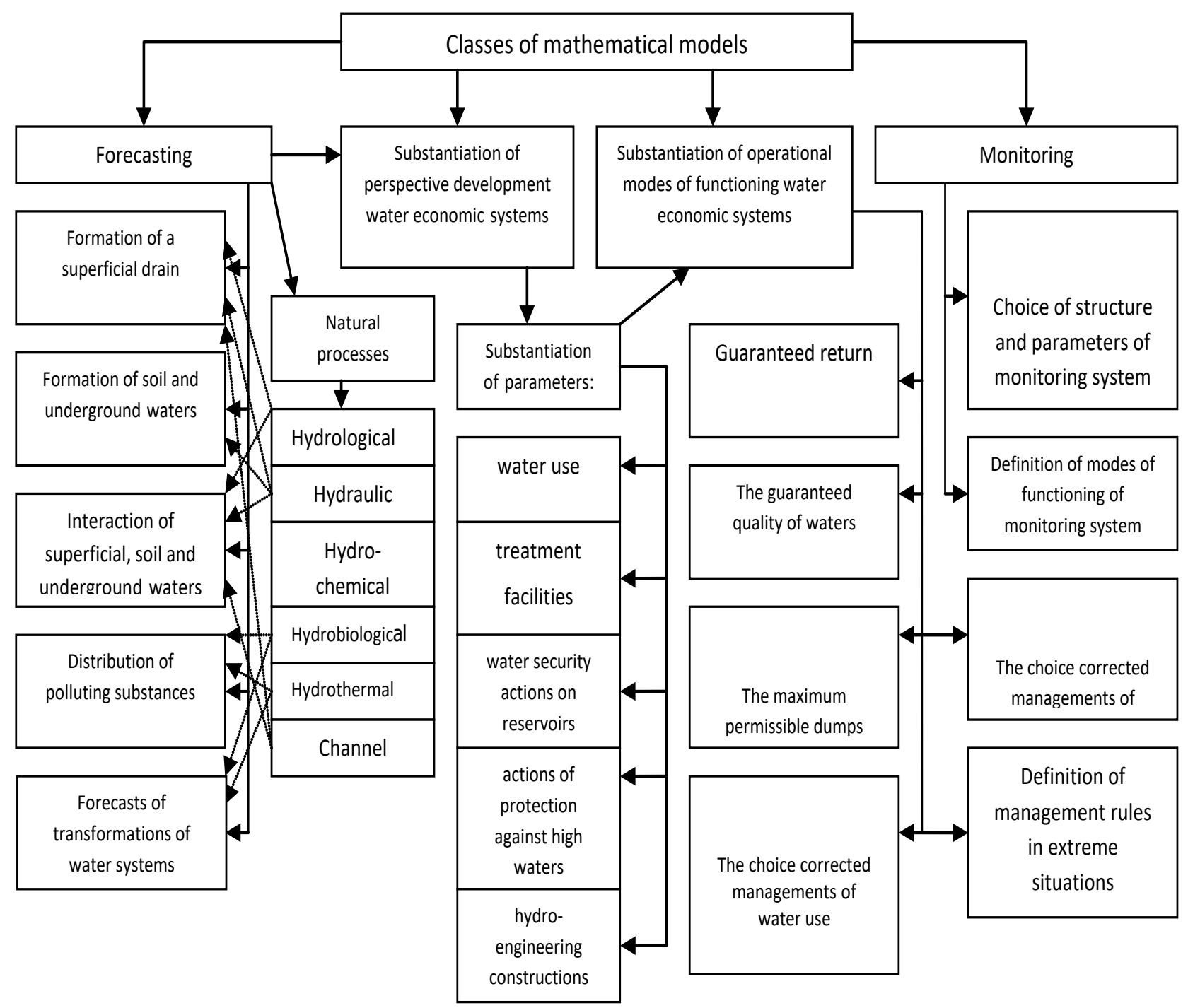

Figure 1. Classification of mathematical models of water resources management ${ }^{1}$.

acceptance of definitive decisions remains for the person - the Person, Making the Decision (PMD), or a group of persons - collective PMD. Such decision, as a rule, is accepted as a result of numerous computing experiments with models with carrying out of iterative procedures.

The basic problems of a water economic management generate following classes of the mathematical models necessary for the decision of water economic problems: forecasting, substantiations of parameters and modes water economic systems, and also models of development of monitoring (Figure 1).

Forecasting models describe various natural processes: hydrological, hydraulic, hydro chemical, hydro biological, hydrothermal and others. Actually forecasting models are intended for research of a complex of processes of formation superficial, soil, under soil, an underground drain and their interaction, and also distribution of polluting substances in the water environment, an estimation 


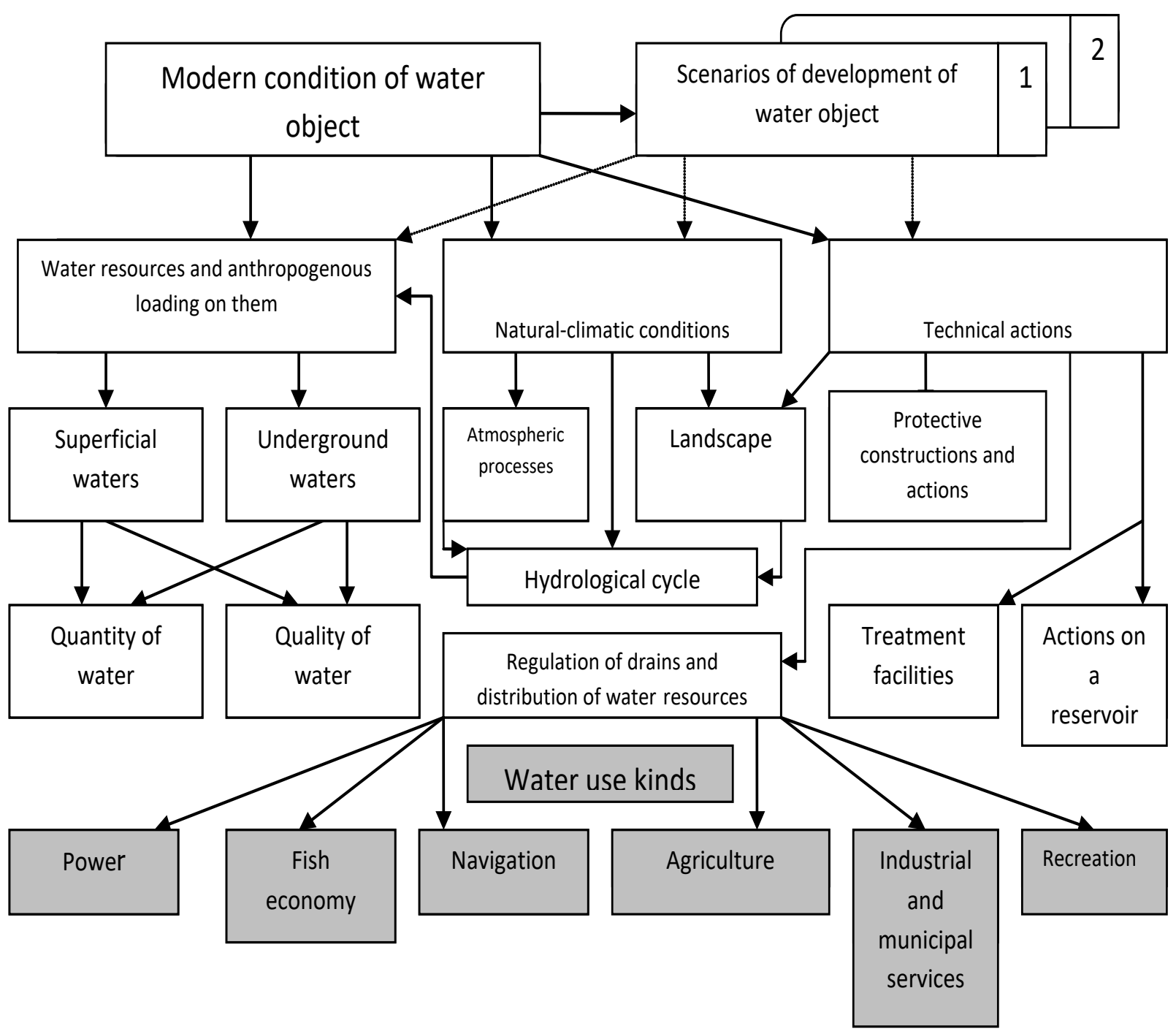

Figure 2. Methodology of research of problems of a sustainable development of water economic systems ${ }^{1}$.

of assimilated potential of water objects and transformations water ecosystems. Forecasting models concern type imitating where multidimensional research of functioning of object is carried out, and also its responses to a variation exohenical setting parameters. Other classes of mathematical models comprise both imitating, and optimizing models. The essence of the last is reduced to comparison of variants and a choice of the best of them according to any system of preferences. These models are conditionally subdivided into models of a substantiation of structure and parameters of system and a choice of modes of its functioning ${ }^{3-6}$. Such division is characteristic and for models of monitoring development ${ }^{7}$. The substantiation of parameters of water economy systems development is based on data of complex monitoring and results of forecasting modeling, and also on scenarios of development of corresponding region (Figure 2).

Among proved parameters characteristics of water users, actions for protection and restoration of waters, protection against their harmful influence, and also technical parameters of clearing and hydraulic engineering constructions are allocated. As almost in all water objects 
actions have the complex character, the resulted division is conditional. For example, into structure of parameters of a water basin enter such as useful volume, a high-rise mark of a dam crest, throughput and a design of a waste construction, etc., each of which can be carried to the own unique class. In real problems which describe mathematical models, the choice of all or parts of the listed classes of parameters can be carried out. Many publications are devoted to the description of similar mathematical models.

The substantiation of operational modes of functioning water economy systems is carried out on the basis of the chosen variants of perspective development of objects and monitoring systems. Corresponding models take the form, both optimization and imitation problems. In concrete computer realizations they can act independently, or as program blocks as a part of problems of a choice of parameters and system structure. Among the problems defining modes of functioning of water economic systems is possible to allocate a substantiation of the guaranteed return $^{8}$ substantiation of the guaranteed quality of water resources and sizes of maximum permissible dumps of polluting substances in water objects ${ }^{9}$, the choice corrected managements of water use ${ }^{10}$. The substantiation of operational modes of water economy systems functioning is often carried out with use of imitating models ${ }^{11}$. It is possible to carry to similar models also definition of rules of management by elements of water economic system at occurrence of extreme situations ${ }^{12}$.

\section{Conclusion}

The research spent by us, shows, that modeling of water use systems is extremely important problem at the present stage, especially in the conditions of a hot climate. Our conclusions allow to present results of rational water resources management.

Thus, exact and objective modeling of rational water use will help to avoid conflicts which can inevitably occur if not to solve the questions connected with use of the Tran boundary Rivers in territory of the Central Asia.

\section{Acknowledgement}

The author gratefully acknowledges the Philosophical Society of Uzbekistan, Department of Ecology, Department of Informatics and applied programming and Department of Philosophy and science methodology of the National University of Uzbekistan named after Mirzo Ulugbek for providing support. The author also thank Prof. Said Mamashakirov from the National University of Uzbekistan for his kindly suggestions for the research, Dr. Valentina G. Priazhinskaya, Head of Water Recourses Management Laboratory in Water Problems Institute of the Russian Academy of Sciences, Moscow, Dr. David M. Yaroshevskii, Senior Researcher in Water Recourses Management Laboratory of Water Problems Institute of the Russian Academy of Sciences, Moscow, and Dr. Leonid K. Levit-Gourevich, Principal Expert in Center of Hydro technical Structures Register and Water Cadastre, Moscow for demonstrating how to express in figures classification of mathematical models of water resources management and sustainable development of water economic systems.

\section{References}

1. Priazhinskaya VG, Yaroshevskii DM, Levit-Gourevich LK. Computer modeling in water resources management. Russian Academy of Sciences Physical and Mathematical Literature Publishing Company. Moscow; 2002. p. 1-494.

2. Yaroshevskii DM, Levit-Gurevich LK, Ostrovskii GM. Projecting of optimum development of small rivers water resources using computers. (Specific Aspects of Hydrological Calculations for Water Economy Projecting). Leningrad: Gidrometeoizdat AJNESCO Press; 1981. p. 607-14.

3. Haith DA. Environment systems optimization. John Wiley and Sons, New York; 1982. p. 1-290.

4. Mathematical models and management methods the large-scale water objects, Novosibirsk: Nauka; 1987. p. 196.

5. Economic instruments for environmental protection [Internet]. [cited 2018 Dec 15]. Available from: https:// www.worldcat.org/title/economic-instruments-for-environmental-protection/oclc/21763569. 
6. Venitsianov EV, Levit-Gurevich LK. Concept of a system for monitoring hydro-objects. Melioratsiya i Vodnoe Khozyaistvo. 1998; 3:48,49.

7. Khranovich IL. Upravlenie vodnymi resursami. Potokovye modeli (Water Resource Management: Flow Models). Moscow: Nauch. Mir; 2001. p. 1-295.

8. Velikanov AL, Korobova DN, Poizner VI. Modelirovanie protsessov funktsionirovaniya vodokho-zyaistvennykh sistem (Modeling of the Processes of Water System Functioning), Moscow: Nauka; 1983. p. 1-271.
9. Shnaidman VM. Simulation model for management of a chain of reservoirs. Journal of Water Resource. 1991; 3:16875.

10. A.E. Kosolapov, A.V. Kuvalkiy, Regulation of high waters on the river Don in Perfection of operation of hydromeliorative systems methods in Works of YNIIGM, Novocherkassk (in Russian); 1981. p. 71-9. 